University of Nebraska - Lincoln

DigitalCommons@University of Nebraska - Lincoln

Architectural Engineering -- Faculty Publications

Architectural Engineering and Construction,

Durham School of

2003

\title{
Acoustic Communication in Panthera tigris: A Study of Tiger Vocalization and Auditory Receptivity
}

\author{
Edward J. Walsh \\ Boys Town National Research Hospital, walsh@boystown.org
}

Lily M. Wang

University of Nebraska, Iwang4@unl.edu

Douglas L. Armstrong

Henry Doorly Zoo

Thomas Curro

Henry Doorly Zoo

Lee G. Simmons

Henry Doorly Zoo

See next page for additional authors

Follow this and additional works at: https://digitalcommons.unl.edu/archengfacpub

Part of the Architectural Engineering Commons

Walsh, Edward J.; Wang, Lily M.; Armstrong, Douglas L.; Curro, Thomas; Simmons, Lee G.; and McGee, JoAnn, "Acoustic Communication in Panthera tigris: A Study of Tiger Vocalization and Auditory Receptivity" (2003). Architectural Engineering -- Faculty Publications. 38.

https://digitalcommons.unl.edu/archengfacpub/38

This Article is brought to you for free and open access by the Architectural Engineering and Construction, Durham School of at DigitalCommons@University of Nebraska - Lincoln. It has been accepted for inclusion in Architectural Engineering -- Faculty Publications by an authorized administrator of DigitalCommons@University of Nebraska Lincoln. 


\section{Authors}

Edward J. Walsh, Lily M. Wang, Douglas L. Armstrong, Thomas Curro, Lee G. Simmons, and JoAnn McGee 


\title{
145th Acoustical Society of America Meeting, Nashville, TN \\ April 28 - May 2, 2003
}

\section{Acoustic Communication in Panthera tigris: A Study of Tiger Vocalization and Auditory Receptivity}

\author{
Edward J. Walsh - walsh@boystown.org \\ Developmental Auditory Physiology Laboratory \\ Boys Town National Research Hospital \\ 555 North 30th Street \\ Omaha, NE 68131 \\ Lily M. Wang \\ University of Nebraska; College of Engineering and Technology \\ Douglas L. Armstrong, Thomas Curro, Lee G. Simmons \\ Henry Doorly Zoo \\ JoAnn McGee \\ Boys Town National Research Hospital \\ Popular version of paper 4aAB3 \\ Presented Thursday morning, May 1, 2003 \\ 145th ASA Meeting, Nashville, TN
}

Introduction: To adults and children alike, tigers are one of the best-known members of the animal kingdom. It may be surprising, then, to learn that we have a lot to discover about their hearing and the acoustics of their vocalizations. To help fill in the gaps in our knowledge, we are in the midst of a study that is focused on the characterization of the vocal properties and hearing capabilities of a subset of surviving tiger subspecies, namely the Siberian, Bengal, Sumatran and the Indochinese tigers. We are hoping that our findings will not only add to a deeper understanding of these mysterious, solitary hunters, but will allow us to contribute to their preservation. However, this is not a small task given the seriousness of their endangerment. 
Successfully communicating with prospective mates and competitors in the field poses a significant challenge to solitary hunters like free-ranging tigers whose hunting territories can be extensive - especially in the case of the Siberian subspecies whose members occupy the deciduous forests of eastern Russia. In that regard, the environmental transmission characteristics of low frequency and infrasonic acoustical signals (acoustic events that contain energy below the frequency range of human hearing) are ideally suited to support long distance communication among widely separated individuals, and tigers have long been recognized as a group that may have developed a vocal repertoire allowing them to establish and maintain hunting territories, identify and associate with mates, and provide females of the species with dependent cubs the opportunity to escape the infanticidal intentions of non-paternal males. Although the results of middle and inner ear studies suggest that low frequency acoustic energy is preferentially processed by the inner ears of tigers, the capacity of individuals to perceive low frequency and infrasonic acoustic events has not been determined and the overall frequency range over which tigers successfully navigate their acoustic landscape has been largely unknown until recently.

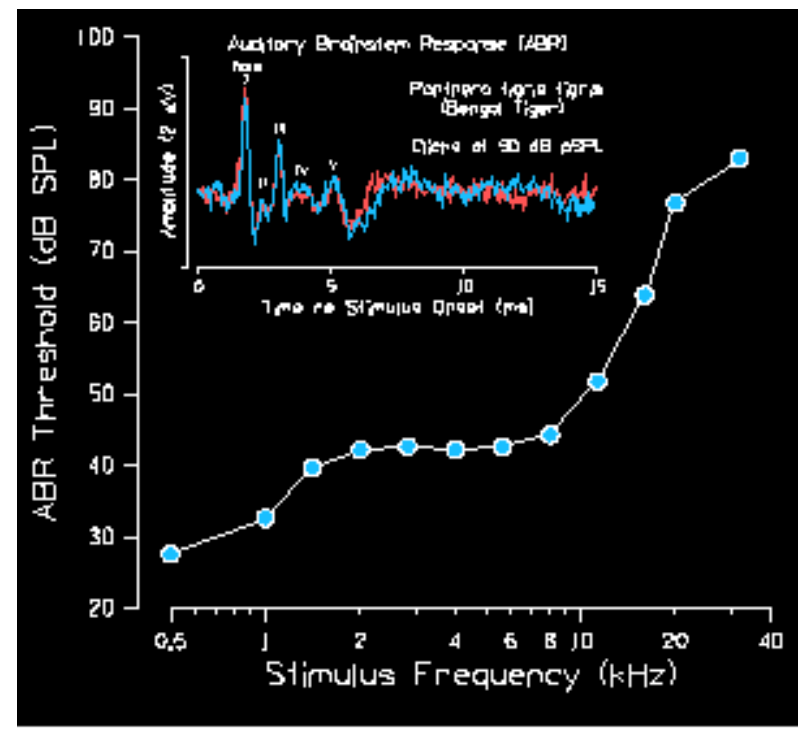

Using a tool commonly employed to assess the hearing of infants, the audible spectrum of sounds that tigers respond to was determined at least in part - by analyzing the auditory brainstem response (ABR), a sound elicited brain potential recorded from the scalp of anesthetized Siberian, Sumatran and Bengal tigers as a part of this investigation. The response itself consists of a series of precisely timed voltage peaks that represent the summed electrical activity of excited neurons distributed along the auditory pathway from the VIIIth nerve to the auditory cortex. An example of an ABR recorded from a Bengal tiger, along with a Threshold vs. Frequency Curve, also known as an audiogram, is shown in the figure to the left. Audiograms representing each of the tiger subspecies studied were sufficiently similar to allow data to be pooled and the generation of the "average tiger audiogram" shown here. As can be seen in the figure, tigers are relatively insensitive to acoustic signals containing predominantly high frequency energy (e.g., 32 kiloHertz) and sensitivity gradually improves as tone burst frequency is decreased with animals being most sensitive to the lowest frequency studied thus far, 500 Hertz, clearly confirming that the most sensitive portion of the tiger's "range of hearing" lies in the low frequency portion of their audible spectrum. Furthermore, the shape of the average tiger audiogram and the relative size of their inner ears (i.e., their cochleae) suggests that individuals may - and probably do - hear acoustic events carried by signals in the near infrasonic and the infrasonic range. An investigation to assess low frequency auditory receptivity is the focus of ongoing research intended to more completely determine the limits of auditory performance in tigers. 
Although more work is required to completely map the low frequency boundary of tiger hearing, it is relatively clear that at least a subset of surviving tiger subspecies produce prodigious amounts of low frequency and infrasonic acoustic energy in their utterances, most notably in the form of roars. Although the vocal repertoire of the tiger is considerable, consisting largely of grunts and growls, roars and moans, snarls and chuffs, and hisses and gasps, the spectral diversity of utterances comprising these categories is limited. Unlike the spectrally complex vocalization patterns of many other animals, notably represented by birds and bats, tigers produce sounds that are spectrally "full," that is they contain energy in a continuous, broadband spectrum ranging from infrasonic to ultrasonic frequency bands. The acoustic energy contained in growls, roars and a friendly greeting known as chuffing, or prusten, produced by an adult male Siberian tiger are compared in a series of spectrograms (graphic displays illustrating how the distribution of acoustic energy at different frequencies changes over time) and associated spectral analyses of selected utterances in the following plots.

In the plot to the right, the spectral characteristic of a roar is depicted graphically. Although the utterance contains a large amount of acoustic energy in the low frequency band - the intense, "yellow hot" band at the lower boundary of the spectrogram - it is notable that this communication signal contains significant acoustic energy in higher frequency bands as well. Examination of the associated spectrum of the roar relative to the background noise in the recording environment (see "spectral analysis") shows that the peak acoustic power of that utterance is contained in a band around $300 \mathrm{Hertz}$, similar to the frequency

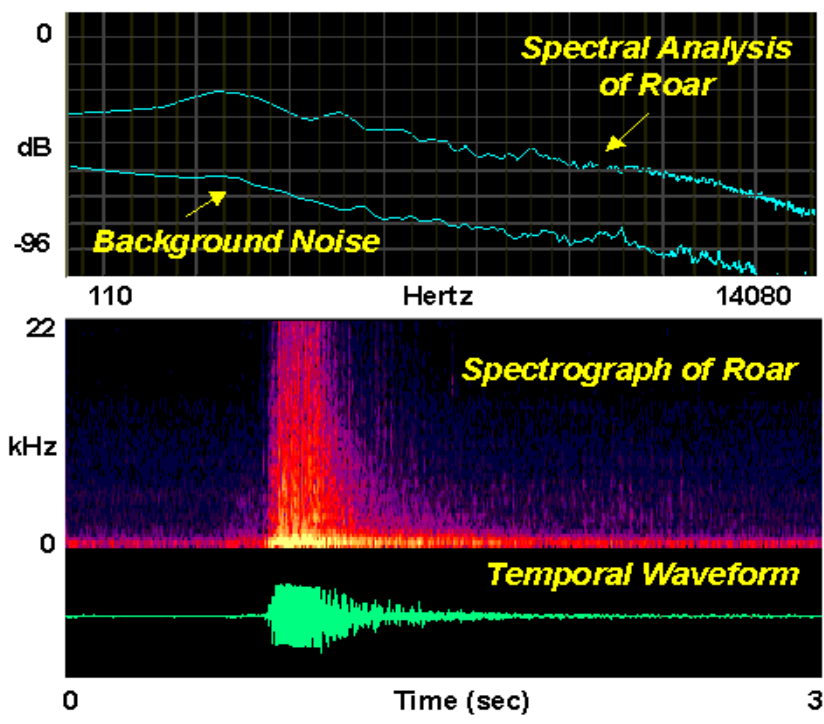
range that tigers appear to be most sensitive to acoustic events. Click on the speaker icon to hear a sample of the roar and note the low level growl (an utterance with considerable energy in the very low frequency/infrasound range) that follows the roar - this sequence is typical of a roaring tiger and most likely serves to even further intimidate a rival.

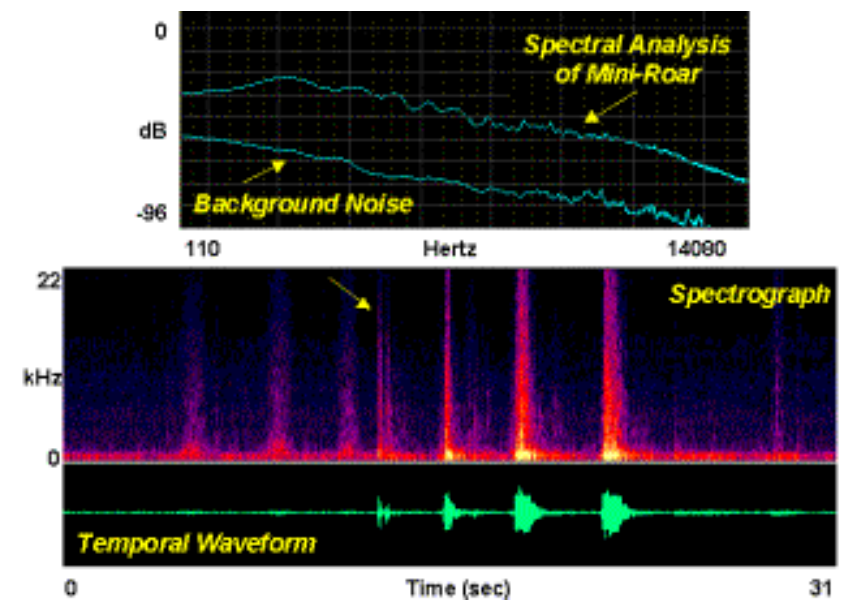

In the figure to the left, an interesting, continuously recorded series of vocal utterances illustrate the diversity of the tiger's vocal repertoire. The segment begins with three breathy utterances that are spectrally characterized by a nearly flat band of low frequency energy extending out to roughly 800-900 Hertz. These are followed by a sequence of four roars, each escalating in production intensity in sequence. In the first "mini-roar" (see arrow), the cat produces two 
brief syllables and a follow-up short, low-level growl that leads to a sequence of three brief but very impressive roars. It is interesting that the spectral characteristics of the "mini-roar" share features of the breathy utterance (i.e., relatively flat spectrum out to about $700 \mathrm{Hertz}$ ) and the full bodied roar that produces peak acoustic energy in a band around $300 \mathrm{Hertz}$, a frequency region that - again - tends to match the most sensitive portion of the big cats' audiometric range thus far studied. The prussing or chuffing sounds of a Siberian in a neighboring cage can be heard on the trailing edge of the record.

Still another typical vocal sequence produced by a Siberian tiger is illustrated in the figure to the right. The record begins with three breathy growls (yellow arrows) that are followed by four very brief, energetic roar bursts (and associated cage rattling) showing the same

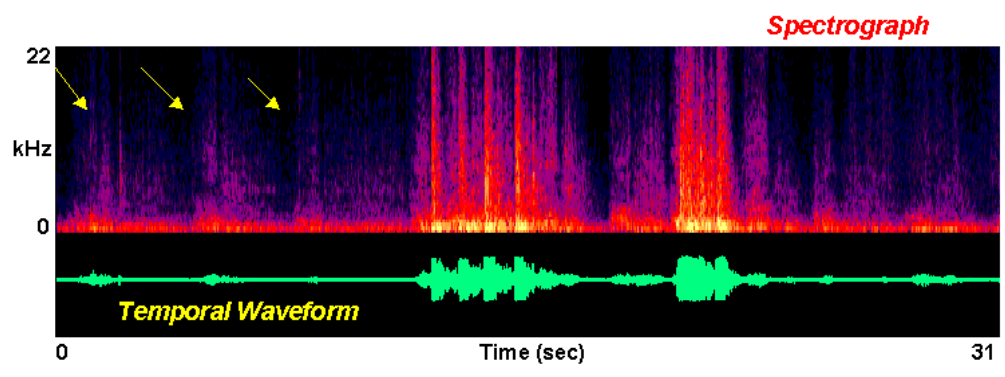
power peak at $\sim 300 \mathrm{Hertz}$ as in other roar records. The "growl" is distinctive relative to the "roar" in that growls are produced at a lower level and do not show the 300 Hertz energy peak that is characteristic of roars.

zLast, a spectrogram representing the friendly flutter of a "chuff" sequence, a very low level greeting call made by passing expired air through both the nose and lips, is shown on the left. A "chuff" sounds like the tiger's version of the "raspberries" The peak energy contained in the greeting lies in the low frequency band and acoustic power drops gradually off as higher and higher frequency bands are measured. Note that while each of the utterances considered here is distinctive, all tend to contain acoustic energy in the low frequency bands, confirming, as it were, the importance of this portion of the audible spectrum.

One of the short-term goals of our research is to determine if the temporal and/or spectral pattern of utterances like those illustrated here contain an "acoustic fingerprint" that will allow the discrimination of individuals on the basis of their vocal characteristics. If such discrimination efforts prove to be successful and reliable, arrays of remote acoustic monitoring devices could be used as the centerpiece of a census-monitoring program in their natural habitat. However, before serious attention can be paid to the issue of acoustics as a conservation tool, it is important to characterize the auditory and vocal attributes of these magnificent animals generally. 